\title{
Safe intra-hospital care in context of vulnerability to socio-environmental disasters: implications for nursing
}

\author{
Assistência intra-hospitalar segura em contexto de vulnerabilidade a desastres socioambientais: \\ implicações para a enfermagem \\ Asistencia intrahospitalaria segura en el contexto de vulnerabilidad a los desastres socioambientales: \\ implicaciones para la enfermería
}

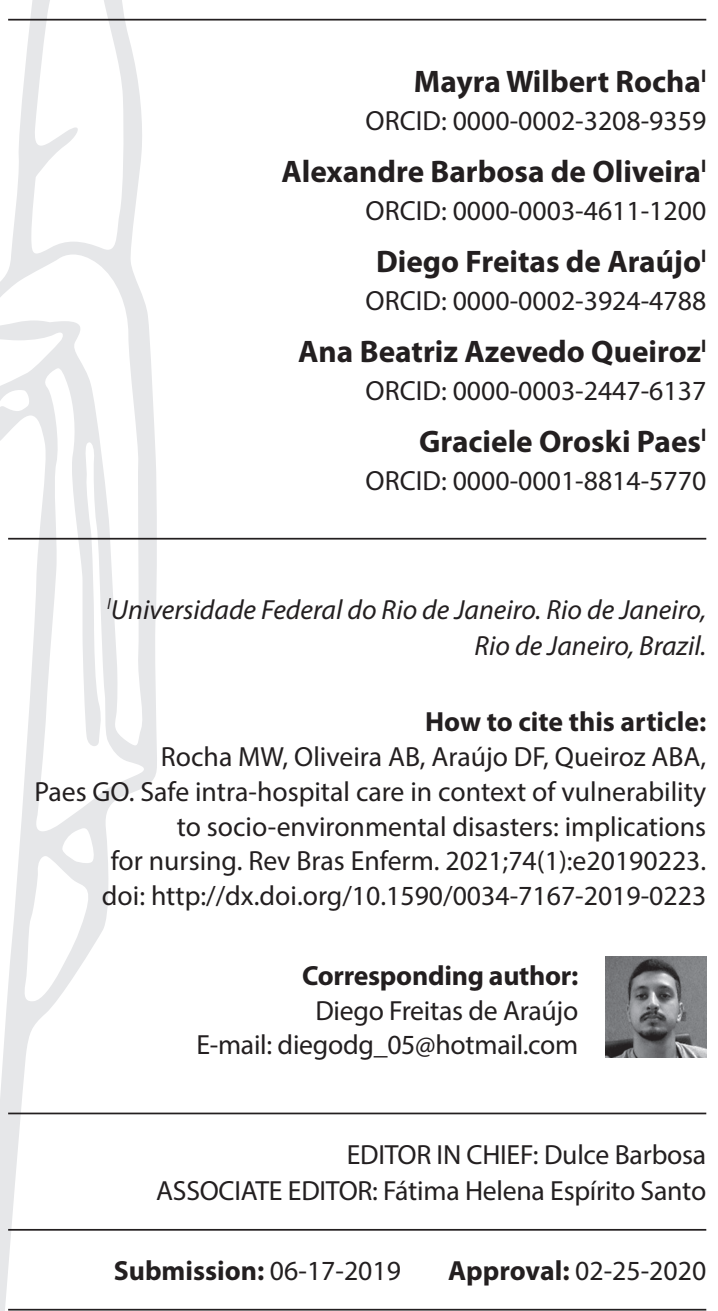

Submission: 06-17-2019 Approval: 02-25-2020

\begin{abstract}
Objectives: to analyze the factors involved in safe intra-hospital care, in a context of vulnerability to socio-environmental disasters and their implications for nursing. Methods: a cross-sectional study of a descriptive and exploratory nature. Semi-structured interviews were conducted with 49 nursing professionals from a hospital in the mountainous region of the state of Rio de Janeiro (Brazil), which suffered a significant impact from a socio-environmental disaster in January 2011. Data were processed by software IRaMuTeQ. Results: aspects related to disaster assistance were presented through a thematic chunk with four classes, through descending hierarchical classification. Conclusions: for better nursing response in socio-environmental disasters, in an intra-hospital setting, investments for training and continuing education should be prioritized; adequate provision and provision of human, material and technological resources; psychological support for professionals after such events; appropriation of nursing competencies for the development of advanced practices in disasters and effective risk management.

Descriptors: Nursing; Hospitals; Safety; Disasters; Disaster Vulnerability.
\end{abstract}

\section{RESUMO}

Objetivos: analisar os fatores intervenientes na assistência intra-hospitalar segura, em contexto de vulnerabilidade a desastres socioambientais e suas implicações para a enfermagem. Métodos: estudo transversal, de natureza descritiva e exploratória. Foram desenvolvidas entrevistas semiestruturadas com 49 profissionais de enfermagem de um hospital da região serrana do estado do Rio de Janeiro (Brasil), que sofreu significativo impacto de desastre socioambiental em janeiro de 2011. Os dados foram tratados pelo software IRaMuTeQ. Resultados: os aspectos relacionados à assistência em desastres foram apresentados por meio de bloco temático com quatro classes, através de classificação hierárquica descendente. Conclusões: para melhor resposta da enfermagem em desastres socioambientais, em cenário intra-hospitalar, devem ser priorizados investimentos para capacitação e educação permanente; previsão e disponibilização adequada de recursos humanos, materiais e tecnológicos; suporte psicológico para profissionais após tais eventos; e apropriação de competências de enfermagem para o desenvolvimento de práticas avançadas em desastres e efetivo gerenciamento de riscos.

Descritores: Enfermagem; Hospitais; Segurança; Desastres; Vulnerabilidade a Desastres.

\section{RESUMEN}

Objetivos: analizar los factores que intervienen en la atención hospitalaria segura, en un contexto de vulnerabilidad a los desastres socioambientales y sus implicaciones para la enfermería. Métodos: estudio transversal, descriptivo y exploratorio. Se llevaron a cabo entrevistas semiestructuradas con 49 profesionales de enfermería de un hospital en la región montañosa del estado de Río de Janeiro (Brasil), que sufrió un impacto significativo de un desastre socioambiental en enero de 2011. Los datos se trataron utilizando el software IRaMuTeQ. Resultados: los aspectos relacionados con la asistencia en desastres se presentaron a través de un bloque temático con cuatro clases, a través de una clasificación jerárquica descendente. Conclusiones: para una mejor respuesta de enfermería en desastres socioambientales, en un entorno intrahospitalario, se deben priorizar las inversiones en capacitación y educación permanente; la previsión y disponibilidad adecuada de recursos humanos, materiales y tecnológicos; el apoyo psicológico para profesionales después de tales eventos; y la apropiación de habilidades de enfermería para el desarrollo de prácticas avanzadas en desastres y la gestión eficaz de riesgos.

Descriptores: Enfermería; Hospitales; Seguridad; Desastres; Vulnerabilidad ante Desastres. 


\section{INTRODUCTION}

On January 11 and 12, 2011, heavy rains hit the mountainous region of the state of Rio de Janeiro (Brazil), causing drastic floods and landslides. Among the municipalities affected, seven declared a state of public calamity ${ }^{(1)}$. As a result, numerous buildings, housing and public infrastructure were completely destroyed, and about 1,000 citizens lost their lives ${ }^{(2)}$. In Nova Friburgo, one of the cities that suffered the greatest effects of the disaster, there were approximately 428 deaths, reporting 241 disappearances and finding 4,528 displaced and 3,800 homeless ${ }^{(3)}$.

This disaster was considered the largest in Brazil's history in relation to the high number of people affected ${ }^{(4)}$. Previously, the worst disaster of natural origin (geological and hydrological type) had occurred in 1967, in the city of Caraguatatuba, on the coast of the city of São Paulo, when more than 400 people lost their lives. Since then, no other event of this typology has occurred in the country, with a high number of deaths ${ }^{(5)}$.

In the disaster in the mountainous region in 2011, the main public hospital in Nova Friburgo underwent serious flooding. Nevertheless, the unit concentrated most of the people affected in search of care. The hospital's emergency department of had to be closed and patients had to be evacuated to hospital units in other municipalities. At the time, it was evident the need for previous development of plans for disaster response in the hospital setting, involving in their matrices of responsibility health professionals, including the nursing team, due to the care and management nature of their activities.

Commonly, disasters of this typology tend to cause extreme disorders in intra-hospital care, which has mobilized international bodies and the academic interest and representative bodies of the profession to discuss the competencies of nursing professionals at such events.

In disasters, it is necessary to consider a continuum assistance defined by actions of promotion, prevention, treatment and rehabilitation, and mediated by care strategies that recommend safe care flows to users and professionals themselves, in addition to guidance to them on the most effective procedures in the control/treatment of injuries. Therefore, such actions should be structurally oriented to the specific phases of disasters: prevention/ mitigation and preparedness (pre-incident); response (incident); recovery and reconstruction/rehabilitation (post-incident), considering vulnerability to such situations, i.e., the likelihood of a particular community or geographic area being affected by a threat or potential risk of disaster ${ }^{(6-7)}$.

For this study, emphasis was placed on the preparation phase, considering the specificities of nursing work and local conditions for better response to possible future situations of natural origin disasters, since the mountainous region of the state of Rio de January is characterized by heavy rains in the summer periods, unstable and landslide-prone soils, and geomorphological history of events of this nature. Moreover, issues related to governance and irregular occupations and constructions in risk areas contribute to increasing vulnerability to disasters, and consequently to the increase in people affected ${ }^{(8)}$.

Given this setting, investment in health facility safety in the most vulnerable regions is a fundamental aspect, in order to enable them to remain in operational conditions even in the face of a disaster, for which structural aspects (columns, beams, walls, slabs, foundations), non-structural (electrical, hydraulic and sanitary networks, ventilation systems, air conditioning, furniture, medical and laboratory equipment, supplies used for the diagnosis and treatment) and functional (technical and administrative organization of personnel to respond to situations, development of emergency/contingency plans, permanent education actions, among others). In this sense, the approach of nursing interventions centered on safe intra-hospital care is also a key point ${ }^{(9)}$.

The research is in line with the Pan American Health Organization recommendations for the development of safe hospitals in the face of disasters, and the World Health Organization and the International Council of Nurses on the competencies to be developed by nursing professionals in disaster situations, at the time that is consistent with the Marchai Framework 201520130 premises for disaster risk reduction, to which Brazil is a signatory ${ }^{(7,9-10)}$.

\section{OBJECTIVES}

To analyze the factors involved in safe intra-hospital care, in a context of vulnerability to socio-environmental disasters and their implications for nursing.

\section{METHODS}

\section{Ethical aspects}

Regarding ethical aspects, all participants were duly informed about the objective of the study and signed the Informed Consent Term. In order to guarantee anonymity, the identification of the participants was performed by the letter "I" out of "interviewee", with the sequential number of interview occurrence. The research was approved by the Research Ethics Committee on April 25, 2017.

\section{Search typology}

This is a descriptive and exploratory cross-sectional study with a qualitative approach.

\section{Setting}

A public hospital was elected in the city of Nova Friburgo, which is located in the mountainous region of Rio de Janeiro, which suffered significant impact and assisted most of the people affected by the disaster that occurred in January 2011.

\section{Data sources and eligibility criteria}

Data were collected in October 2017 by individual interview forms, which was conducted in the hospital unit at a time and environment conducive to dialogue. Forty-nine nursing professionals participated in the study. Professionals who are part of the nursing care and supervision teams of this hospital, stationed in emergency and surgical sectors, places most affected during the 2011 disaster and, in general, the most likely to be required 
in disaster situations of this nature, were included in the study. The exclusion criteria referred to nursing professionals who chose not to participate in the research for personal and/or psychological reasons.

\section{Data analysis}

For data processing, we used the software IRaMuTeQ。 (Interface de R pour les Analyses Multidimensionnelles de Textes et de Questionnaires). This software is used as support for lexical analysis of textual data, which consists of a specific form of data processing of transcribed verbal material from different types of collection, such as interviews, written texts, observations, documents, essays, among others. IRaMuTeQ ${ }^{\circ}$ allows a new methodological positioning regarding the classical division between quantitative and qualitative in data analysis, since it favors the quantification and use of statistical calculations on essentially qualitative variables, the texts ${ }^{(11)}$.

The program groups the words by semantic similarity, allowing five typologies of analysis: research of group specificities and confirmatory factor analysis, word cloud, classical textual statistics, analysis of word similarity and Descending Hierarchical Classification (DHC). In this study, we opted for DHC analysis, which allows textual corpus organization in a hierarchical way and in semantic classes, sequencing, in order of relevance, the words with greater representativeness within the generated classes, and classifying text segments (parts with relevant meanings) according to their respective vocabularies ${ }^{(12)}$.

From the words and segments of text articulated to the classes revealed by software, identification and analysis of textual domains was carried out, as well as to the interpretation of the meanings, that is, of the factors involved in the safe intra-hospital care, in a context of vulnerability to socio-environmental disasters, and its implications for nursing. These meanings were nominated and categorized through their meanings in the following classes: class 2 (lack of investment in the qualification of nursing professionals for intra-hospital assistance in disasters); class 1 (precariousness of human and material conditions and resources for assistance); class 4 (determining aspects of safety in intra-hospital disaster care) and class 3 (need for guidance and psychological support for the practice of disaster nursing).

Therefore, the program enabled the identification and reformatting of text units, reconfiguring the material of the interviews in text segments grouped by classes. The dendogram generated by IRaMuTeQ ${ }^{\circ}$, relative to corpus, allowed to visualize the $\mathrm{DHC}$ design in these four classes, which served as a support for the interpretative approach ${ }^{(11)}$.

\section{RESULTS}

Among the study participants, 40 (81.63\%) are female nursing professionals and nine (18.36\%) male. The predominant age group is 30 to 39 years. In relation to training and professional performance, 10 (20.4\%) correspond to nurses working in care, six (12.2\%) nurses who develop activities focused on supervision/ management, 24 (48.9\%) are nursing technicians and nine (18.3\%) are nursing assistants. Of the 49 interviewees, 31 (63.2\%) more than 11 years of nursing graduates. With regard to disaster training, only seven (14.2\%) of the total performed some course or training and 11 (22.4\%) participated in academic events related to the theme.

As for the data processed through IRaMuTeQ ${ }^{\circ}$, the thematic chunk that addressed the factors involved in safe intra-hospital care, in the context of vulnerability to socio-environmental disasters, and its implications for nursing consisted of four semantic classes, which represents $67 \%$ of the entire corpus considered for analysis. Correlations among the classes indicated two main groupings of the data. One between classes 2 and 1, and the other between classes 4 and 3 . The complementarity verified between the classes of the two groups indicates coherence of semantic content among them. The following dendogram shows this division and the dominant lexiconfor each class.

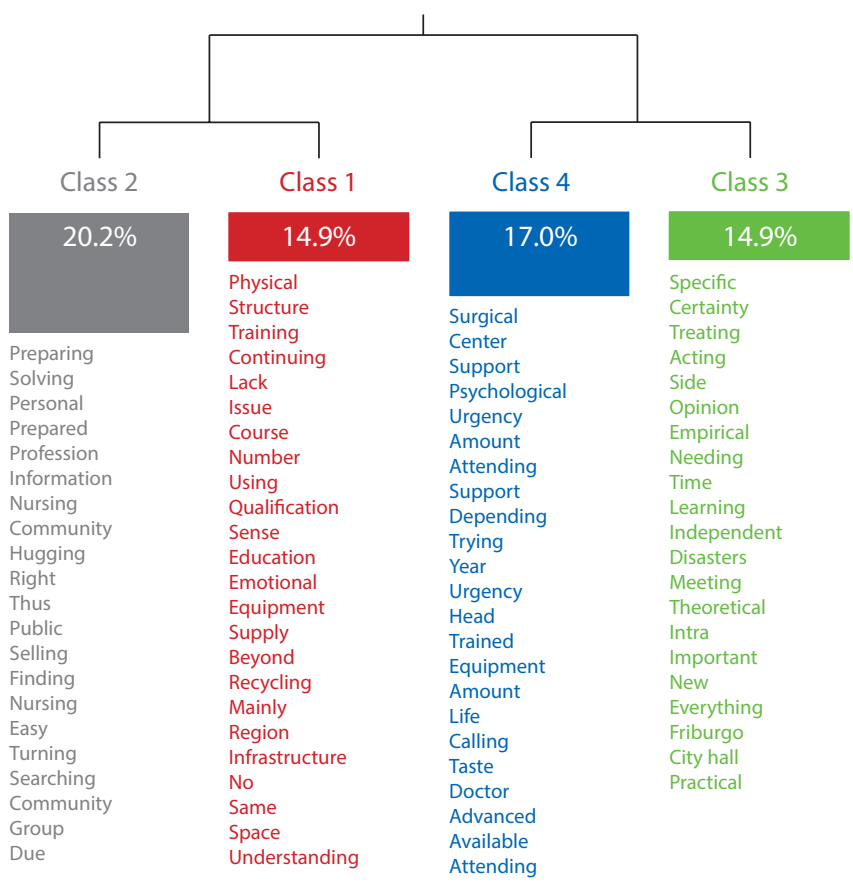

Figure 1 - Descending Hierarchical Classification's dendogram with the most significant words of the interviews with nursing professionals, Nova Friburgo, Rio de Janeiro, Brazil, 2018

The following are the words, text segments, and characteristics related to classes $2,1,4$, and 3, according to the order in which they were generated through $\mathrm{DHC}$.

In the constitution of class 2, 143 text segments were defined, representing $30.23 \%$ of the corpus analysis of the thematic chunk alluding to the four classes. The most representative variables were supervising nurses, aged between 50 and 59 years. Class characterization is expressed by the words with greater representation highlighted from its text segments, such as preparing (chi2 $=43.1$ ), solving (chi2 $=30.55$ ), personal (chi2 $=28.48$ ), prepared (chi2 $=27.32$ ), profession (chi2 $=23.82$ ) and information (chi2 = 22.42). The text segments and terms of greater representativeness express hows nursing teams perceived the lack of preparation of both professionals and the hospital to provide adequate health care to the large number of victims in serious condition, in addition to aspects related to nursing practice for disaster activities. 
Despite the forces that everyone has united, the doctors, nursing, the hospital was not prepared at the time, and today much less. (I. 18)

About the preparation of the team, it was a very improvised thing, because no one was prepared. I think we have to have more training. This hospital is the only one that has here, which receives the entire population. [...] Here, often, the professional is not very prepared. (I. 09)

Nursing knows the whole structure of the hospital. However, it is not prepared for a major tragedy. (I. 27)

Skills, I cannot tell you, because there are so many details at this point of tragedy that we cannot even enumerate what could be done. (I. 39)

Class 1 integrates 105 text segments, which refers to $22.19 \%$ of the corpus thematic chunk analysis. The variable with the highest representativeness was the 'dressing room' sector. The words that characterize this class are physical (chi2 $=97.72$ ), structure (chi2 =64.06), training (chi2 $=63.02$ ) and professional (chi2 = 59.23). The text segments and the words with the highest representativeness manifest the lack of investments for effective disaster care. Inadequate hospital organization in terms of physical structure and human and material resources, and insufficient promotion of strategies aimed at professional qualification for care by the institution in these situations were the two highlighted points.

The question here is the logistics of the unit. Lack of employee, lack of equipment, lack of supplies, among other things more... (I. 04)

[...] We do not have structure for the patients that we already have. So, for a catastrophe, there is not even, besides material... there are days when you don't have a respirator. (E.24)

[...] I think, in addition, lectures and practical courses. This part of training for teams, simulation, should be done. (I. 32)

You have to pay for the training course. If it's your shift, you still have to pay someone to stay on your shift. So, there's no way we can afford it. (I. 03)

Class 4 consisted of 120 text segments, which is related to $25.36 \%$ of the thematic chunk data. Only one variable had greater representativeness in this class, the 'operating room' sector. The words with the highest representation detached from the text segments are surgical (chi2 $=72.44)$, center (chi2 $=62.75$ ), support (chi2 $=31.59$ ), psychological (chi2 $=24.73$ ), urgency (chi2 $=20.09$ ), quantity (chi2 = 18.88) and attending (chi2 = 13.71). They express more affected sites and factors that have shaken safety in intra-hospital care due to the extreme situation, its severity and high number of patients. The operating room stood out, because trauma victims were referred for surgeries immediately upon admission, which brought potential losses and risks during care, as indicated in the following text segments:

He was walking to the operating room, because most of them were amputations, because things had fallen on top of his leg, arm. Then we immediately referred to the operating room. (I. 33)
In most cases, we tried to keep the technique, but it was very difficult, because the operating room became very dirty, too much mud. We didn't have time to worry about keeping the sector clean and so on. We, as far as possible, tried to maintain a technique not to take contamination, but it was very difficult. (I. 13)

Depending on the conditions, we will act safely for the patient. But we depend on the conditions as well. (I. 14)

Class 3 consisted of 105 text segments, which represented $22.19 \%$ of the thematic chunk analysis corpus. The variable with the highest representativeness was the age of participants between 60 and 69 years. The words of greater representativeness, which characterize this class, are specific (chi2 $=40.47$ ), certainty (chi2 $=30.55$ ), treating (chi2 = 28.82), and acting (chi2 = 24.13). The text segments, which bring these words in their bulge, reveal the need for greater support for nursing professionals to be able to deal with specific situations of eventual disasters, usually extreme, chaotic and out of the routine. According to the text segments of this class, there is a certain gap with regard to psychological support to act in disasters.

What we ask and need a lot is this, is guidance and psychological support. (I. 20)

First one must discuss the psychological issue. [...] Doing a psychological treatment for these people. There are many people who still speak with a certain weight when it comes to this subject. (I. 10)

One should treat very psychological, because if you do not have psychological to deal with this situation, everything goes away. (I. 12)

Look, if I say that we feel psychologically prepared, I'm lying. (I. 45)

\section{DISCUSSION}

The results presented point especially to challenges to be faced in relation to the lack of psychological support for assistance in disaster situations, the impact suffered by nursing professionals in relation to the severity of the countless cases, the ethical-legal commitment of safety standards aimed at care, inadequate hospital infrastructure and the lack of incentives for the preparation of professionals to act in such occurrences.

Professionals in leadership and supervision positions need to recognize the structural, non-structural and functional aspects of the hospital units where they operate, in order to prevent and mitigate possible damage, and achieve safer and more adequate responses in disaster situations. This demand is in favor of initiatives appointed by the Pan American Health Organization aimed at the development of technologies and risk reduction strategies in health facilities in the Americas ${ }^{(9)}$.

Preparation plans and emergency response to such events need to be collectively developed in order to ensure continuity of care. Practical approaches include from the implantation of its own systems for screening, transporting and evacuating affected people, to promoting regular and systematized training with the creation of voluntary brigades for rapid response in critical occurrences, understanding that each hospital unit has its functional and architectural particularities. 
Furthermore, it is necessary to have control of which services the unit is properly able to offer in a response situation, recognize public policies and current laws, and share practices and knowledge that involve assistance in contexts of as well as credible information with teams before, during and after the event. Thus, strategies of continuing education, training and updating for assistance and research development have the potential to collaborate greatly with the reduction of risks at the local and institutional level.

In the event of disasters, the hospital emergency plan should usually be triggered and resources made available promptly ${ }^{(13)}$. For this purpose, health units need to be organized preliminary, in order to ensure that flows between the various services operate in a harmonious and effective manner, and to structure possible supports from other nearby hospital units, ensuring the quality of user care. Among the necessary material resources are equipment, medicines, blood products and supplies, in addition to the organization of extra areas, inside and outside the hospital unit, to manage the flow, screening, treatment and evaluation of patients, as well as such as additional personnel resources and relocation of professionals in hospital units requiring greater intervention $^{(13)}$.

Commonly, nurses and their teams do not feel safe enough to act, due to the very complex conditions emanating from the disaster, and the knowledge and skills they have for decision-making accurately and immediately. In general, this condition is aggravated by the few opportunities for training and institutional preparation exercises developed, for example, through simulated exercises that foster feasible disaster situations ${ }^{(14-15)}$.

This situation is consistent with that of a study that explored the point of view of nurses about the challenges and resources to carry out their responsibilities in disasters, highlighting a case of hospital evacuation of a U.S. medical center during the Hurricane Sandy in 2012. The research attested to the relevance of previous training, but also the need to develop specific policies on the roles of nurses in disasters, skills to lead teams in these situations and incorporation of already simulated in nursing schools ${ }^{(16)}$. These aspects are also highlighted in research developed with private hospitals in Saudi Arabia, which evaluated their preparedness for internal and external disasters to the units, highlighting the collaboration between hospitals in the region in relation to the response to such events, and revealing the lack of monitoring exercises of hospital teams for emergency situations ${ }^{(17)}$.

Also, it is important to highlight that institutional support focused on the mental health of professionals is also a pressing demand. Disaster work tends to involve attempts to suppress emotions, tragic and unexpected contact with mass death, human suffering, lack of resources and security, and the need to account for the rescue of as many lives as possible, which, for often determines an extremely stressful, distressing and even automated, focused and goal-oriented work ${ }^{(13)}$. These aspects were widely perceived in the discursivity of the study participants, when they reported their experiences in the case of the 2011 disaster in Nova Friburgo.

In cases of disasters, the first psychological care can be provided by nursing professionals themselves, who are usually the ones who are in greater numbers in health facilities and who, due to the nature and relevance of their work, have more demands for human care and safety, since disasters that occur in communities tend to be brought into hospitals. With this in mind, both ensuring adequate psychological support to these professionals, and instrumentalizing them on the care of patients in such situations, is a fundamental aspect to consider to improve their self-confidence and self-efficacy in disaster preparedness and strengthen their psychological capacity and mental well-being ${ }^{(18)}$.

Although resources for intra-hospital care are scarce, safety is a fundamental aspect that needs to be emphasized in disaster contexts, in order to reduce to an acceptable minimum the risk of unnecessary harm associated with health care. In the case of the disaster in Nova Friburgo, the risk of serious adverse events related to surgical procedures, infections and the use of devices was present in the hospital setting investigated ${ }^{(19)}$. At the time, the professionals tried to develop aseptic techniques, even though there were barriers that greatly hindered such action, such as the presence of large amounts of mud in the hospital and a high number of people affected transported directly into the operating room on wooden doors and platforms.

This risk was aggravated due to the impaired organization of that health facility. In general, hospitals are expected to function as a safe environment before, during and after disasters. At the time of the occurrence of such an event, studies report that the failure of this usually refers to inappropriate institutional response plans, damage to buildings, unavailability of personnel, lack of water supply, medicines and other supplies, failure of equipment and telecommunications system, difficulty in managing and coordinating with relevant community sectors and bodies ${ }^{(19-20)}$.

These factors tend to worsen when health facilities do not have the proper support in terms of public funds to remain active in normal situations. Therefore, in cases of disasters, in addition to the sudden increase in the demand for care, the marks of the social determinants of health and precarious governance are also felt, which is something that well distinguishes the poorest countries and, so to speak, considerably more vulnerable to disaster.

Another aggravating factor identified was the difficulty of access of a relevant part of the professionals, both to arrive and to leave the hospital, as a result of the effects of the disaster in the city. Those who were on duty at the time of the intense rains were emotionally shaken and exhausted by the emergency demands they had to develop, which were aggravated by the incessant arrival of injured people. This impacted the effective availability of nursing teams for hospital care, and consequent organization of the service.

What the statements of the interviewed professionals pointed out are very consistent with the challenges faced in other countries, in several related situations. An example of this occurred in the United States of America with the passage of Hurricane Katrina and Sandy. Hospitals hardly get enough staff to provide minimal care, and those who are available work in the most extreme conditions, since professionals usually fail to reach the health units where they work ${ }^{(21-22)}$.

In such cases, states and cities, and the health facilities must adopt specific policies and legislation to address this type of problem, standardizing the response, and defining and delegating responsibilities. An inventory of all available employees, 
to assist teams during a disaster, should be compiled for each location and health institution, even if they have nurses and other health professionals properly trained for this purpose is not such an easy task ${ }^{(23)}$.

Moreover, in relation to disaster risk reduction strategies, some alternatives have been pointed out with a focus on preparing nurses to work within the local health systems, guided by institutional and community demands. Such strategies are mediated by undergraduate and graduate programs, by proposals for incorporating the theme into training curricula and by verifying the need for continuous and advanced training with high fidelity simulation ${ }^{(24-26)}$.

Despite such initiatives, contemporary recognition of the dramatic effects of climate change and the impacts of social and environmental disasters globally suggests that health sciences still have much to advance. Therefore, in the case of nursing there is still a long way to go, although it is recognized that disaster settings (particularly wars) have been constituted in important vectors of nursing professionalization ${ }^{(27)}$.

Indeed, one of the goals of disaster nursing is to achieve the best possible level of health for individuals, families and communities involved $^{(18)}$. Thus, the need for empowerment to act in disasters permeates the adoption of strategies that develop skills for mitigation and risk reduction. The sensitization of professionals in this regard should be something to be made possible through daily attitudes and practices, which aim to involve them in relation to the demands of care, in order to support effectively safe intra-hospital care, yet amid the $\operatorname{chaos}^{(28)}$.

In Brazil, although it is listed in the rankings as one of the countries most affected by disasters, whether intensive (if studied in the mountainous region) or extensive (the drought of northeastern Brazil), disaster risk reduction initiatives are still very punctual, little articulated between sectors and agencies, with precarious popular participation and fragile governance, and in the process of knowledge construction and technological investment still timid and delayed. Obviously, all this problem tends to cause unwanted reflexes for intra-hospital care to victims of such occurrences.

Chart 1 - Recommendations for safe intra-hospital care in the context of vulnerability to socio-environmental disasters

\begin{tabular}{|l|l|}
\hline - Identifying the potential risks for assistance in \\
disaster situations, including around the hospital \\
unit, considering environmental aspects. \\
- Planning the attendance of emergency clinical \\
and surgical demands, considering excessive \\
number of victims, diversity and severity of cases. \\
- Ensuring continuity of safe disaster assistance. \\
- Providing first psychological care to victims who \\
are welcomed by the hospital unit. \\
- Developing intervention measures and \\
technologies for the provision of safe care in the \\
intra-hospital setting, including in the screening, \\
transport and evacuation of victims. \\
- Observing ethical-legal precepts of professional \\
practice, in order to support decision making and \\
prioritization of care in cases of disasters. \\
- Ensuring the records of the assistance provided, \\
and its safeguard.
\end{tabular}

To be continued
Chart 1 (concluded)

\begin{tabular}{|c|c|}
\hline Education & $\begin{array}{l}\text { - Diagnosing limits of knowledge, and define skills } \\
\text { and skills for disaster intervention. } \\
\text { - Assessing the need for training and obtain } \\
\text { additional resources needed for training. } \\
\text { - Developing training plans and educational } \\
\text { intervention systems for disaster assistance, } \\
\text { considering multidisciplinary approach. } \\
\text { - Conducting periodic simulations and training in } \\
\text { workplaces and in the community. } \\
\text { - Empowering team leaders to integrate } \\
\text { crisis committees and risk management and } \\
\text { management functions. } \\
\text { - Encouraging risk perception practices among } \\
\text { professionals working in the hospital in order to } \\
\text { promote a safety culture. } \\
\text { - Developing and facilitating disaster research. }\end{array}$ \\
\hline Management & $\begin{array}{l}\text { - Paying attention to the structural, non-structural } \\
\text { and functional vulnerabilities of the institution, in } \\
\text { order to protect the lives of patients, professionals } \\
\text { and visitors. } \\
\text { - Ensuring that hospital facilities and their equipment } \\
\text { remain operational, even in cases of intra- or extra- } \\
\text { hospital disasters. } \\
\text { - Assessing the hospital's readiness and develop } \\
\text { actions to expand it when necessary. } \\
\text { - Monitoring measures of forecasting, provision } \\
\text { and contingency of water services, electricity, } \\
\text { telecommunications, among others, as well as } \\
\text { organize and predict stocks of medicines, blood, } \\
\text { supplies, materials and equipment. } \\
\text { - Recognizing warning, alarm and signalling systems } \\
\text { for emergency hospital evacuations. } \\
\text { - Ensuring access and support to means of } \\
\text { emergency transport. } \\
\text { - Developing disaster preparedness and response } \\
\text { plans, as well as protocols for mass casualty care. } \\
\text { - Identifying suspected risks to health and/or the } \\
\text { environment, and report them to the competent } \\
\text { authorities (institutional and public health). } \\
\text { - Defining chain of command and the role of nurses } \\
\text { within the institution's incident control system. } \\
\text { - Creating a disaster response team of the hospital } \\
\text { guided by skills, skills and matrices of responsibilities. } \\
\text { - Developing and making accessible to supervisors } \\
\text { and heads telephone listing of members of the } \\
\text { hospital health teams, to ensure quick and orderly } \\
\text { contact in emergencies. } \\
\text { - Maintaining communication and coordination } \\
\text { strategies with other members of the disaster } \\
\text { response team. } \\
\text { - Establishing/keeping contact with the authorities, } \\
\text { sectors and agencies responsible for local/regional } \\
\text { disaster response. } \\
\text { - Defining psychological support strategies for } \\
\text { profs. }\end{array}$ \\
\hline
\end{tabular}

Moreover, the safety culture is still a fragile point to be carefully considered in the context of health care. Nevertheless, it should be understood as a medium and long-term process, as it often involves structural adjustments in the health system and changes in behavior and attitudes of the professionals involved. Therefore, the amplified debate on the development of nursing skills and competencies in such situations is emergency.

Finally, as contributions to safe intra-hospital care, in a context of vulnerability to socio-environmental disasters, some specific recommendations aligned with nursing practice are pointed out, which can potentially be developed and improved in the field of care, education and management, which are linked to the discursivity of the participants of this study ${ }^{(23)}$. 


\section{Study limitations}

The limitations of this study involve the difficulty of generalizing the specific case that was studied, due to the complexity and multiple aspects involving the various types of socio-environmental disasters, as well as the difficulty of sizing the threats, vulnerabilities and the degree of risk of that disaster situation occurred in January 2011, and how much this event impacted intra-hospital safe care. It is noteworthy that during the data collection in the study setting it was not possible to identify documents or other types of information sources that, in a complementary way, satisfied the fulfillment of the objective of this study, which made it difficult to possible data triangulation process.

\section{Contributions to the nursing area}

It is believed that the development of this study contributes to the recognition of Nursing care more in touch with the needs of intervention in the case of new disasters, hence the preparedness phase is related to the preparation of diagnoses and training plans, contingency and protocols for assisting affected people. In addition, it is expected that the results obtained by the development of this research will stimulate the continuous training of Nursing professionals in the area of emergencies and disasters and thus increase the perspective of improving safety in hospital care in the face of social and environmental disasters.

Indeed, the assumption of management and response actions aimed at the development of professional preparation, response and training strategies for situations of hospital emergencies in general, can enhance the increase of the capacity of Nursing professionals to deal with the structuring needs of contingency plans, responsibility matrices, effective communication of risks, psychosocial support for professionals and definition of specific competencies for the health team and social staff in situations responding to emergencies and disasters in hospital plants.

\section{FINAL CONSIDERATIONS}

The study brought to light some problem situations usually faced by health facilities in contexts of socio-environmental disasters, and pointed out specific recommendations for the preparation of nursing professionals to work in these situations. The recognition of the limits for disaster care and management in an intra-hospital setting was a key point revealed by the study participants. Among the challenges are the care and displacement of patients during the collapse of hospital units, the conditioning of professionals to deal with stress situations, the adequate forecasting and availability of human and material resources, the use of technologies aimed at safe care, the situational diagnosis of the architectural and functional security of the hospital, the implantation of preparation and response plans, investment in training strategies and continuing education on the subject, and the consideration and alignment of specific nursing competencies for the development of advanced practices and effective risk management at all stages of the cycle of a disaster, before, during and after the event.

In this perspective, in order for nursing teams to be able to respond to such events, greater investments from hospital institutions are needed, so that greater theoretical and scientific support can be made possible for practice, development of more resolving initiatives, increased empowerment and confidence of these professionals through emergency situations that demand the need for coordinated conduct, which can maximize the quality of disaster care, in relation to basic or specialized care.

It is recommended that measures aimed at care and advanced methods of learning and management be strategically and operationally developed to give effectiveness to the constant preparation of nursing professionals to work in disaster situations, especially in hospital settings. Indeed, this investment contributes to a better response, risk reduction and promotion of human security in the context of disasters.

\section{REFERENCES}

1. Fraga NC, Simas FAO, Jayme NS, Silveira HM. Geografia e acidentes socioambientais no Brasil - Vale do Itajaí/SC (2008) e Região Serrana/ RJ (2011):uma apreciação socioambiental dos desastres naturais e ações antrópicas. Rev Presença Georg.2015;2(1):83-102. doi: 10.36026/ rpgeo.v2i1.1293

2. Katarine K, Madalena M, Duque DEL, Andrade M, Queiroz SJDE. Os desastres naturais e seus impactos à saúde pública brasileira. Rev Ciências Ambient Saúde. [Internet]. 2014 [cited 2019 Apr 8];41(2):307-13. Available from: http://seer.pucgoias.edu.br/index.php/estudos/ article/view/3386/1972

3. Viana VJ. Gestão de risco de desastres no Brasil: leitura das estratégias locais de redução de riscos de inundação em Nova Friburgo, Rio de Janeiro [Internet] [Tese]. Rio de Janeiro (RJ):Universidade do Estado do Rio de Janeiro; 2016[cited 2019 Apr 8]. Available from: http://www. nuredam.com.br/files/publicacoes/teses/TeseVivianeJapiassuViana.pdf

4. Carmo RL, Anazawa TM. Mortality due to disasters in Brazil: what the data reveals. Cien Saude Colet. 2014;19(9):3669-81. doi: 10.1590/1413-81232014199.07432014

5. Moura CA. Avaliação de tendência a enchentes das bacias hidrográficas do município de Caraguatatuba (SP). Rev Geogr [Internet]. 2013 [cited 2019 Jun 6];30(2):123-38. Available from: https://periodicos.ufpe.br/revistas/revistageografia/article/view/229012/23414

6. Bandeira AG, Marin SM, Witt RR. Vulnerability to natural disasters: implications for nursing. Ciên Cuid Saúde. 2014;13(4):776-1. doi: 10.4025/ cienccuidsaude.v13i4.22135

7. World Health Organization (WHO). International Council of Nursing (ICN). ICN Framework of disaster Nursing Competencies. Geneva: WHO; 2009. Available from: http://www.wpro.who.int/hrh/documents/icn_framework.pdf 
8. Freitas LE, Netto ALC. Reger Córrego Dantas: uma ação coletiva para enfrentamento de ameaças naturais e redução de desastres socioambientais. Ciên Trópico [Internet]. 2016 [cited 2019 May 14];40(1):165-189. Available from: https://fundaj.emnuvens.com.br/CIC/article/view/1588/1287

9. Organización Panamericana de la Salud (OPAS). Guía del evaluador hospitales seguros frente a desastres [Internet]. 2008[cited 2019 Jun 6]. Available from: http://www.planeamientohospitalario.info/contenido/referencia/ish-guia.pdf

10. United Nations Office for Disaster Risk Reduction (UNISDR). Sendai Framework for Disaster Risk Reduction 2015 - 2030 [Internet]. 2015 [cited 2019 Jun 6]. Available from: https://www.unisdr.org/we/inform/publications/43291

11. Souza MAR, Wall ML, Thuler ACMC, Lowen IMV, Peres AM. The use of IRAMUTEQ software for data analysis in qualitative research. Rev EsC Enferm USP. 2018;52:e03353. doi: 10.1590/s1980-220×2017015003353

12. Camargo BV, Justo AM. IRAMUTEQ: um software gratuito para análise de dados textuais. Temas Psicol. 2013;21(2):513-518. doi: 10.9788/ TP2013.2-16

13. Hammad KS, Arbon P, Gebbie K, Hutton A. Nursing in the emergency department (ED) during a disaster: a review of the current literature. Aust Emerg Nurs J. 2012;15(4):2350-44. doi: 10.1016/j.aenj.2012.10.005

14. Alzahrani F, Yiannis K. Emergency nurse disaster preparedness during mass gatherings: a cross-sectional survey of emergency nurses' perceptions in hospitals in Mecca, Saudi Arabia. BMJ Open. 2017;7(4). doi: 10.1136/bmjopen-2016-013563

15. Zarea K, Beiranvand S, Sheini-jaberi P, Nikbakht-nasrabadi A. Disaster nursing in Iran: challenges and opportunities. Australas Emerg Nurs J. 2014;17(4):190-6. doi: 10.1016/j.aenj.2014.05.006

16. VanDevanter N, Raveis VH, Kovner CT, McCollum M, Keller R. Challenges and Resources for Nurses Participating in a Hurricane Sandy Hospital Evacuation. J Nurs Scholarsh. 2017;49(6):635-43. doi: 10.1111/jnu.12329

17. Shalhoub AA, Kin AA, Alaska YA. Evaluation of disaster preparedness for mass casualty incidents in private hospitals in Central Saudi Arabia. Saudi Med J. 2017;38(3):302-306. doi:10.15537/smj.2017.3.17483

18. Said NB, Chiang VCL. The knowledge, skill competencies, and psychological preparedness of nurses for disasters: a systematic review. Int Emerg Nurs. 2019. doi: 10.1016/j.ienj.2019.100806

19. Harada, MDJ, Pedreira M. Assistência Segura: uma reflexão teórica aplicada à prática. Segurança do Paciente e Qualidade em Serviços de Saúde [Internet]. 2013[cited 2019 Jun 6]. Available from: http://www20.anvisa.gov.br/segurancadopaciente/images/documentos/livros/ Livro1-Assistencia_Segura.pdf

20. Lakbala P. Hospital workers disaster management and hospital nonstructural: a study in Bandar Abbas, Iran. Glob J Health Sci. 2016;8(4):221-6. doi:10.5539/gjhs.v8n4p221

21. Mbewe C, Jones M. Hurricane Sandy: competencies needed to contend with natural disasters. Acad Medical-Surgical Nurses[Internet]. 2013 [cited 2019 May 22];22(4):1-5. Available from: https://www.amsn.org/sites/default/files/private/medsurg-matters-newsletter-archives/ julaug13.pdf

22. Rocha MW. Preparação de profissionais de Enfermagem para assistência intra-hospitalar em situações de desastres socioambientais [dissertação]. Rio de Janeiro (RJ):Universidade Federal do Rio de Janeiro; 2018. Available from: https://pesquisa.bvsalud.org/portal/ resource/pt/biblio-964359

23. Oztekin SD, Larson EE, Akahoshi M. Japanese nurses 'perception of their preparedness for disasters: quantitative survey research on one prefecture in Japan. Japan J Nurs Sci. 2016;13(3):2-11. doi: 10.1111/jjns.12121

24. Witt RR, Gebbie KM. Tailoring curricula to fit health professionals needs in a disaster: a proposal for Brazilian nurses. Rev Gaúcha Enferm. 2016;37(1):e56229. doi: 10.1590/1983- 1447.2016.01.56229

25. Park H, Kim J. Factors influencing disaster nursing core competencies of emergency nurses. App Nurs Res. 2017;37:1-5. doi: 10.1016/j. apnr.2017.06.004

26. Lourenço MBC, Pinto CMI, Silva Jr OC, Lourenço LHSC, Paes GO, Oliveira AB. The inclusion of Brazilian flight female nurses in the second world war: challenges and achievements. Esc Anna Nery. 2017;21(4):1-8. doi: 10.1590/2177-9465-ean-2017-0008

27. Baack S, Alfred D. Nurses' Preparedness and Perceived Competence in Managing Disasters. J Nurs Scholarsh. 2013;45(3):281-7. doi: 10.1111/ jnu.12029 